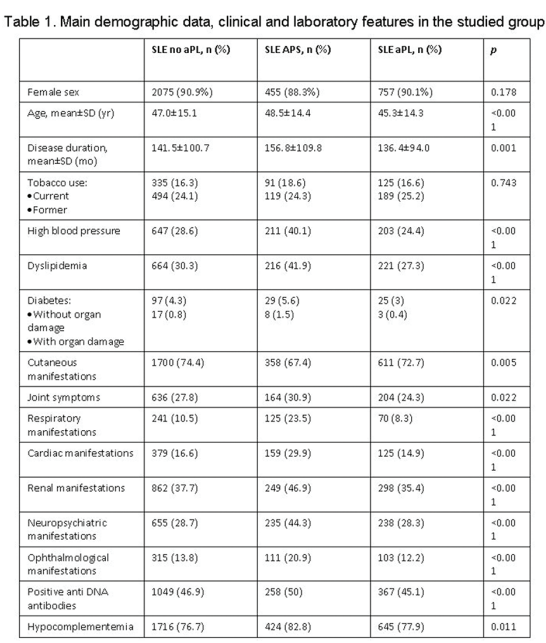

Conclusion: SLE-APS patients show a more severe clinical profile with higher frequency of major organ involvement and more damage accrual than SLE-aPL and SLE no APL.

Disclosure of Interests: : Leyre Riancho-Zarrabeitia Grant/research support from: Abbvie, Pfizer, UCB, MSD, GSK, Amgen, Roche travel grants, Victor Martinez Taboada: None declared, Iñigo Rua-Figueroa: None declared, Fernando Sánchez-Alonso: None declared, María Galindo-Izquierdo: None declared, Juan Ovalles: None declared, Alejandro Olivé Grant/research support from: ND, Consultant for: ND, Paid instructor for: ND, Speakers bureau: ND, Antonio FernandezNebro: None declared, Jaime Calvo Consultant for: Bristol-Myers Squibb, Janssen, Celgene, Sanofi Genzyme, Speakers bureau: Bristol-Myers Squibb, Raúl Menor Almagro: None declared, Eva Tomero Muriel: None declared, Esther Uriarte Isacelaya: None declared, Alina Boteanu: None declared, Mariano Andres: None declared, Mercedes Freire González: None declared, Gregorio Santos Soler: None declared, Esther Ruiz Lucea: None declared, Mónica Ibañez Barceló: None declared, Ivan Castellví Consultant for: I received fees less than 5000 USD as a consultant for Kern and Actelion, Paid instructor for: I received fees less than 2000USD as a instructor for Boehringer -Ingelheim, Novartis and Gebro, Speakers bureau: ND, Carles Galisteo: None declared, Víctor Quevedo Vila: None declared, Enrique Raya: None declared, J. Narváez Consultant for: BristolMyers Squibb, Lorena Expósito: None declared, José A Hernandez Beriain: None declared, Loreto Horcada: None declared, Jose M Pego-Reigosa: None declared DOI: 10.1136/annrheumdis-2019-eular.2475

\section{OP0250 \\ INFLUENTIAL FACTORS IN PROMOTING TREAT-TO- TARGET FOR SYSTEMIC LUPUS ERYTHEMATOSUS VIA EMPOWERING PATIENTS: A COHORT STUDY FROM CHINA BY SMART SYSTEM OF DISEASE MANAGEMENT (SSDM)}

Jianlin Huang ${ }^{1}$, Tong $\mathrm{Xie}^{2}$, Qiang Shu ${ }^{3}$, Jing Yang ${ }^{4}$, Yongfu Wang ${ }^{5}$, Hongzhi Wang ${ }^{6}$, Xiangyuan Liu' ${ }^{7}$, Cheng Zhao ${ }^{8}$, Xinwang Duan ${ }^{9}$, Guosheng Wang ${ }^{10}$, Rui Wu ${ }^{11}$, Yanjie Hao ${ }^{12}$, Yuhua Jia ${ }^{13}$, Fei Xiao ${ }^{13}$, Lingyun Sun ${ }^{14}$, SSDM Collaboration Group. ${ }^{1}$ The sixth Affiliated Hospital of Sun Yat-sen University, Guangzhou, China; ${ }^{2}$ Affiliated hospital of Guangdong medical University, Zhanjiang, China; ${ }^{3}$ Qilu Hospital of Shandong University, Jinan, China; ${ }^{4}$ Central Hospital of Mian Yang, Mian Yang, China; ${ }^{5}$ The First Affiliated Hospital of BaoTou Medical College, Bao Tou, China; ' JiaXing First Hospital, Jiaxing, China; ${ }^{7}$ Peking University Third Hospital, Beijing, China; ${ }^{8}$ The First Affiliated Hospital of Guangxi Medical University, Nanning; ${ }^{9}$ The Second Affiliated Hospital of Nanchang University, Nanchang, China; ${ }^{10}$ Anhui Provincial Hospital, Hefei, China; ${ }^{11}$ The First Affiliated Hospital of Nanchang University, Nanchang, China; ${ }^{12}$ Peking University First Hospital, Beijing, China; ${ }^{13}$ Shanghai Gothic Internet Technology Co., Ltd., Shanghai, China; ${ }^{14}$ The Affiliated Drum Tower Hospital of Nanjing University Medical School, Nanjing, China

Background: T2T is routine in RA, but no comparable standard has been defined for SLE. In 2015, the definition of Lupus Low Disease Activity State (LLDAS) was generated by Asia-Pacific Lupus Collaboration, and the preliminary validation demonstrated its attainment to be associated with improved outcomes in SLE. A SLEDAI-2K score lower than 4 is the main criteria for LLDAS. SSDM is an interactive mobile disease management application, including application systems for both the doctors and patients. The patients can perform self-assessment, including SLEDAI and medical records entry through the mobile application. The data is synchronized to the SSDM of authorized rheumatologists and stored in cloud database.
Objectives: To evaluate the patterns of T2T and related influential factors among SLE patients after applying SSDM in real world.

Methods: Patients were trained to master SSDM by rheumatologists in clinics. The first assessment for SLEDAI was performed as the baseline. Patients were required to perform repeated assessments after leaving the clinics.

Results: From July 2015 to Jan 2019, 1,090 SLE patients from 88 hospitals were followed up for more than 12 months through SSDM, and the results were summarized in Table 1. The ratio of T2T achievers was $52.84 \%(576 / 1,090)$ at the baseline and improved significantly to $68.35 \%(745 / 1,090)$ after a 12 -month follow-up, $p<0.01$. Among T2T achievers at the baseline, $77.08 \%$ (444/576) maintained T2T, and $22.92 \%(132 / 576)$ relapsed. Of patients who didn' $t$ achieve T2Tat baseline, $58.56 \%$ (301/514) of the them achieve T2T after 12-month followup.

The impact of the times of self-assessment for SLEDAI on T2T has been analyzed. The more frequent of the self-assessments being conducted by patients, the higher improvement of T2T rate will be. We performed linear regression analysis of variables in statistics and parameter estimation by least square method. The improvement of T2T rate(y) was positively correlated with times of self-assessment for SLEDAI $(x)$ independently. The regression equation as " $y=0.0324 x+$ $0.0226 \mathrm{R} 2=0.7717 ", p<0.01$. (Figure 1 )

Conclusion: After proactive disease management via SSDM, the rate of T2T in SLE patients increased significantly. Patients with SLEDAI-2K $\leq 4$ score at baseline had a significantly higher retention rate. The patients who performed more self-assessments through SSDM had lower probability of relapse and higher rate of T2T maintaining and achievement. SSDM is a valuable tool for long term SLE follow-up through empowering patients.

Table1:

\begin{tabular}{lcccccc}
\hline $\begin{array}{l}\text { BaselinelLast } \\
\text { follow-up }\end{array}$ & Number & $\%$ & SLEDAI $\leq 4$ & $\%$ & SLEDAl $\geq 5$ & $\%$ \\
\hline SLEDAl $\leq 4$ & 576 & $52.84 \%$ & 444 & $77.08 \%$ & 132 & $22.92 \%$ \\
SLEDAI $\geq 5$ & 514 & $47.16 \%$ & 301 & $58.56 \%$ & 213 & $41.44 \%$ \\
Total & 1090 & $100 \%$ & 745 & $68.35 \%$ & 345 & $31.65 \%$ \\
\hline
\end{tabular}

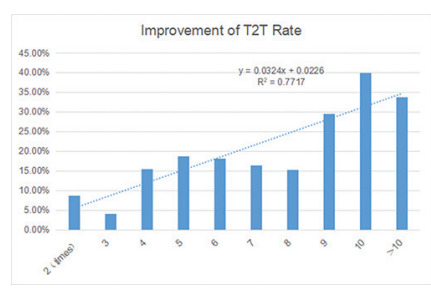

Figure 1

Disclosure of Interests: None declared

DOI: 10.1136/annrheumdis-2019-eular.5257

\section{OP0251 SLE PATIENTS FROM NORTH AMERICA ARE OLDER WITH LESS SEROLOGIC ACTIVITY THAN OTHER POPULATIONS IN INTERNATIONAL CLINICAL TRIALS}

Ewa Olech ${ }^{1}$, Eduard van Rijen ${ }^{1}$, Ali Ashrafzadeh ${ }^{1}$, Alexander Kant ${ }^{1}$, Joan T. Merrill'. ${ }^{1}$ IQVIA, Rheumatology Center of Excellence, Las Vegas, United States of America; ${ }^{2}$ Oklahoma Medical Research Foundation, Oklahoma City, United States of America

Background: Regional differences have been identified as potential confounders of SLE clinical trial results. Recently, no difference between treatment and placebo was observed in the US lupus patients when a significant treatment effect was observed in Europe ${ }^{1}$.

Objectives: To compare SLE serologic features/markers of active disease between different geographic regions in recent multinational clinical trials.

Methods: Laboratory data of 1005 subjects from four global randomized SLE clinical trials at baseline were examined. Mean/median C3 and C4 complement levels, prevalence of low $\mathrm{C} 3$ or $\mathrm{C} 4$ (Low C3/C4), positive anti-double stranded DNA (DNA), anti-Extractable Nuclear Antibodies (ENA), and high-titer Antinuclear Antibody (ANA $\geq 1: 640)$ in North America (NA) patients were compared to Asia (AS), Latin America (LA), Africa (AF), Western Europe (WE), and Eastern Europe (EE) Results: NA patients were significantly older than patients in LA, AF, or AS but not WE or EE. Not surprisingly, they also had higher complement levels and the lowest rates of low $\mathrm{C} 3 / \mathrm{C} 4$, DNA, ENA, and ANA $\geq 1: 640$. Our data confirm that age is an important factor in the prevalence of low complement and autoantibodies. However, there remained a marked difference in serologic activity between $\mathrm{NA}$ and $\mathrm{EE}$, despite being close in age. 
Asian patients were the youngest, had the lowest complement levels and the highest rate of ENA \& DNA consistent with high disease activity. Low complement, but not DNA, was relatively common in Europe. LA patients, like Asians, had high rates of serologic activity but less incidence of low $\mathrm{C} 3 / \mathrm{C} 4$, suggesting that this population may have intrinsic disease severity without being as acutely active. ${ }^{*}$ Mann-Whitney Rank Sum ${ }^{*}$ Chi-square ${ }^{\#}$ One-way ANOVA on ranks; Med-median p-p value C-comparator $n s$-not significant; Data not corrected for multiple comparisons

Conclusion: SLE patients entering studies from North America are strikingly less likely to have markers of active disease than other regions, raising concerns for their suitability for trials. This appears to be associated, at least in part, with age, although more aggressive treatments cannot be ruled out.

Asian subjects have the greatest prevalence of autoantibodies and low complement. Latin American patients have high prevalence of $A N A \geq 1: 640$ and other autoantibodies, but less evidence of low complements.

These findings may help to explain regional differences in treatment/placebo responses and emphasize the importance of geographical stratification and improved methods to screen out patients unsuitable for SLE trials.

\section{REFERENCE:}

[1] www.immupharma.co.uk

Disclosure of Interests: Ewa Olech Grant/research support from: Bristol Myers Squibb, Eduard van Rijen: None declared, Ali Ashrafzadeh Employee of: Employee of IQVIA, Alexander Kant: None declared, Joan T Merrill Grant/ research support from: Genentech, UCB, GSK, EMD Serono, Pfizer, Celgene, Exagen, Bristol Myers Squibb, Medimmune/Astra Zeneca, Lilly, Amgen, Xencor, Neovacs, Consultant for: Genentech, UCB, GSK, EMD Serono, Pfizer, RemeGen, Celgene, Exagen, Bristol Myers Squibb, Medimmune/Astra Zeneca, Lilly Immupharma, Amgen, Janssen, Sanofi, Neovacs, Anthera, Speakers bureau: UCB, GSK, EMD Serono, Bristol Myers Squibb, Medimmune/Astra Zeneca, Janssen

DOI: 10.1136/annrheumdis-2019-eular.6332

OP0252

\section{NEUROPATHIES IN SYSTEMIC LUPUS} ERYTHEMATOSUS: RESULTS FROM AN INTERNATIONAL, INCEPTION COHORT STUDY

John Hanly ${ }^{1}$, LI Qiuju ${ }^{1}$, LI Su ${ }^{1}$, Murray B Urowitz ${ }^{1,2}$, Caroline Gordon ${ }^{1}$, SangCheol Bae ${ }^{1}$, Juanita Romero-Diaz ${ }^{1}$, Jorge Sanchez-Guerrero ${ }^{1}$, Sasha Bernatsky ${ }^{1}$, Ann E Clarke ${ }^{1}$, Daniel J Wallace ${ }^{1}$, David Isenberg ${ }^{1}$, Anisur Rahman ${ }^{1}$, Joan T Merrill ${ }^{1}$, Paul Fortin ${ }^{1}$, Dafna D Gladman ${ }^{1}$, Ian N. Bruce ${ }^{1}$, Michelle A Petri ${ }^{1}$, Ellen M Ginzler ${ }^{1}$, M.A. Dooley ${ }^{1}$, Kristjan Steinsson ${ }^{1}$, Rosalind Ramsey-Goldman ${ }^{1}$, Asad A Zoma ${ }^{1}$, Susan Manzi ${ }^{1}$, Ola Nived ${ }^{1}$, Andreas Jonsen ${ }^{1}$, Munther Khamashta ${ }^{1}$, Graciela S Alarcon ${ }^{1}$, Ronald F van Vollenhoven ${ }^{1}$, Elisabet Svenungsson ${ }^{1}$, Cynthia Aranow ${ }^{1}$, Meggan Mackay ${ }^{1}$, Guillermo Ruiz-Irastorza ${ }^{1}$, Manuel RamosCasals ${ }^{1}$, S. Sam Lim ${ }^{1}$, Murat Inanc ${ }^{1}$, Kenneth C Kaluniann ${ }^{1}$, Soren Jacobsen ${ }^{1}$, Christine Peschken ${ }^{1}$, Diane L Kamen ${ }^{1}$, Anca Askanase ${ }^{1}$, Chris Theriault ${ }^{1}$, Vernon Farewell ${ }^{1} .{ }^{1}$ Queen Elizabeth II Health Sciences Center and Dalhousie University, Rheumatology/Medicine, Halifax, Nova Scotia, Canada; ${ }^{2}$ University of Toronto Schools, Toronto, Canada

Background: Central nervous system (CNS) involvement accounts for over $90 \%$ of neuropsychiatric (NP) events compared to involvement of the peripheral nervous system (PNS) which accounts for most of the other events. Although there is a large body of work on CNS disease in SLE patients, involvement of the PNS is less well established.

Objectives: In a multi-ethnic/racial, prospective SLE inception cohort, to determine the clinical characteristics, associations and outcomes in different types of peripheral nervous system (PNS) disease.

Methods: Patients were evaluated annually for 19 NP events including seven types of PNS disease. Standardized case definitions and attribution models for each type of PNS event were used. SLE disease activity (SLEDAI-2K), organ damage (SLICC/ACR damage index), autoantibodies, patient (SF-36) and physician (Likert score) assessment of outcome were measured. Time to event and linear regressions were used as appropriate.

Results: Of 1,827 SLE patients, $88.8 \%$ were female, $48.8 \%$ Caucasian. The mean $\pm S D$ age was $35.1 \pm 13.3$ years, disease duration at enrollment $5.6 \pm 4.2$ months and follow-up 7.6 \pm 4.6 years. There were 161 PNS events in 139/1,827 $(7.6 \%)$ patients. The predominant events were peripheral neuropathy $[66 / 161$ $(41.0 \%)]$, mononeuropathy [44/161 (27.3\%)] and cranial neuropathy [39/161 $(24.2 \%)]$ and the majority were attributed to SLE. Multivariate Cox regressions suggested longer time to resolution in patients with prior history of neuropathy, older age at SLE diagnosis, higher SLEDAI-2K scores, and for peripheral neuropathy versus other neuropathies. Neuropathy was associated with significantly lower SF-36 physical and mental component summary scores versus patients without NP events. By physician assessment, the majority of neuropathies 